\title{
Kajian Sosiolinguistik Pemakaian Bahasa Indonesia oleh Penutur Asing dalam Konten Video Youtube
}

\author{
Nugroho Ponco Santoso \\ Pendidikan Bahasa Indonesia, Pascasarjana Universitas Sebelas Maret, \\ Jalan Ir. Sutami 36 A Kentingan, Jebres, Surakarta, 57I26 \\ nugroho.ponco@gmail.com
}

\begin{tabular}{ll}
\hline Informasi artikel & \\
\hline Sejarah artikel: & \\
Diterima & I7-II-2017 \\
Revisi & 3I-3-2018 \\
Dipublikasikan & Mei 2018 \\
\hline
\end{tabular}

\section{Kata kunci:}

Youruber

Penutur asing

Sosiolinguistik

Budaya

\begin{abstract}
ABSTRAK
Penelitian ini bertujuan untuk mengkaji pemakaian bahasa Indonesia oleh penutur asing dalam konten video Youtube. Metode penelitian yang digunakan berupa deskriptif kualitatif dengan pendekatan sosiolinguistik. Sumber data dari penelitian ini adalah video para pembuat konten video di situs jejaring Youtube.com yang disebut juga sebagai Youtuber. Data dikumpulkan dengan cara metode simak dan cakap dengan melihat dari video para Youtuber. Youtuber yang dipilih berdasarkan pertimbangan jumlah pelanggan dan jumlah penonton pada masing-masing video. Data dianalisis untuk dicari bentuk campur kode, alih kode, interferensi dan integrasi bahasa. Hasil penelitian menunjukkan bahwa bahasa Indonesia penutur asing masih dipengaruhi oleh bahasa Inggris serta bahasa daerah, seperti bahasa Sunda dan bahasa Jawa. Penggunaan bahasa daerah tersebut disebabkan karena pengaruh lingkungan dari para Youtuber ini tinggal. Selain itu, munculnya penggunaan bahasa daerah tersebut juga dipengaruhi oleh budaya. Kekhasan lain yang muncul adalah penggunaan bahasa tabu oleh penutur baik menggunakan bahasa asing maupun bahasa daerah berupa penyebutan kata yang berkaitan dengan seksualitas.
\end{abstract}

\section{Key word:}

Youtuber

Foreign Speaker

Sociolinguistics

Culture

\begin{abstract}
The aim of this study is to examine $\mathrm{T}$ the use of Indonesian by foreign speakers in Youtube video content. The research method used is descriptive qualitative with sociolinguistic approach. The data sources from this research are video creators videos on the Youtube.com networking site also known as Youtuber. The data was collected by the method of referring and ably by looking at the video of Youtuber. Youtuber selected based on customer number and audience size on each video. Data were analyzed to find code mixed form, code change, interference and language integration. The results of the study indicate that Indonesian foreign speakers are still influenced by English as well as local languages, such as Sundanese and Javanese. The use of local languages is due to the environmental influence of these Youtubers live. In addition, the emergence of regional language use is also influenced by culture. Another distinctiveness that arises is the use of taboo language by speakers either using a foreign language or regional language in the form of mentions related to sexuality..
\end{abstract}

Copyright (C) 2018 Universitas Ahmad Dahlan. All Right Reserved

\section{Pendahuluan}

Bahasa Indonesia sebagai bahasa resmi bangsa Indonesia memiliki potensi kuat untuk menjadi bahasa Internasional. Potensi tersebut muncul karena beberapa alasan,pertama, Indonesia merupakan salah satu negara yang dinilai strategis sebagai pasar investasi global. Data yang dirilis oleh UNCTAD pada tanggal 7 Juni 2017(Sukmana, 2017) menyatakan Indonesia menempati posisi keempat sebagai negara tujuan investor setelah Amerika Serikat, China, dan India. Hal itu menunjukkan bahwa posisi Indonesia yang semakin kuat di dunia. Kedua, jumlah penduduk Indonesia menempati posisi empat terbesar (Worldbank, 20I8) sebanyak 26I.II5.000 jiwa setelah China, India, dan Amerika Serikat. Ketiga, jumlah mahasiswa asing yang belajar di Indonesia semakin meningkat setiap tahunnya. Sebanyak 6967 surat izin belajar diterbitkan oleh dirjen DIKTI sepanjang tahun 2016 (RISTEKDIKTI, 20I7). Keempat, adanya kerjasama Badan Bahasa dengan berbagai kampus di seluruh dunia untuk menyelenggarakan program kelas BIPA, salah satunya 
di Tiongkok yang mencapai sembilan penyelenggara (Sudaryanto, 2014)

Potensi tersebut juga didukung oleh struktur bahasa Indonesia yang memiliki berbagai kemiripan dengan struktur bahasa Inggris sebagai bahasa internasional seperti penggunaan huruf yang sama, konstruksi bahasa, serta adanya unsur historis. Berbagai Kesamaan tersebut dapat menambah kemudahan penutur asing dalam mempelajari bahasa Indonesia sehingga tidak perlu bersusah payah belajar. Kemajuan teknologi juga semakin mempermudah akses para pebelajar asing dalam mempelajari bahasa Indonesia. Hadirnya internet membuat batasan seperti jarak dan waktu seolah lenyap karena kemampuannya mengakses informasi yang tidak lagi mengenal waktu dan tempat.

Youtube, sebagai situs nomor dua paling populer di seluruh dunia (Alexa, 2017) juga turut menjadi situs yang membantu meningkatkan popularitas bahasa Indonesia untuk penutur asing. Banyak bermunculan berbagai pembuat konten video Youtube -sering disebut sebagai Youtuber- asing yang menggunakan bahasa Indonesia untuk konten videonya. Beberapa penutur asing tersebut bahkan tidak hanya menguasai bahasa Indonesia, tetapi juga menguasai bahasa daerah contohnya bahasa Jawa yang memiliki konstruksi bahasa jauh lebih kompleks dibandingkan bahasa Indonesia.

Para Youtuber dalam membuat konten video berbahasa Indonesia tentu harus memiliki daya kreatifitas agar video yang dimilikinya ditonton dan salurannya dilanggan oleh banyak orang. Kreatifitas ini tentu menuntut para Youtuber membuat konten semenarik mungkin, misalnya menggunakan bahasa Indonesia dicampur dengan bahasa asli yang dia kuasai. Dengan begitu akan muncul kekhasan tertentu yang menjadi ciri maupun karakteristik dari video konten para Youtuber tersebut.

Penggunaan bahasa Indonesia yang bercampur dengan bahasa asli para Youtuber asing merupakan salah satu fenomena bahasa yang menarik untuk dikaji. Terjadinya alih kode dan campur kode tersebut tidak semata-mata disengaja dan terjadi secara spontan (Indefrey \& Gullberg, 2009; Treffers-Daller, 2009) sehingga kadang-kadang tidak disadari oleh penuturnya. Meskipun demikian, alih kode dan campur kode merupakan perilaku paling khas dan merupakan komponen penting dari kompetensi komunikatif penutur bilingual mahir(Gort, 20I2).

Penelitian yang berkaitan dengan alih kode dan campur kode pernah dilakukan oleh Saddhono (2012) berjudul "Kajian Sosiolingustik Pemakaian Bahasa Mahasiswa Asing Dalam Pembelajaran Bahasa Indonesia Untuk Penutur Asing (Bipa) Di Universitas Sebelas Maret" yang meneliti mengenai alih kode campur kode dari mahasiswa asing dalam pembelajaran BIPA. Hasil penelitian tersebut menunjukkan bahwa bahasa Inggris digunakan sebagai bahasa mediasi ketika muncul kesulitan antara dosen dan mahasiswa. Selain bahasa Inggris, bahasa Jawa juga digunakan dalam pembelajaran karena lingkungan pendidikan berada di Surakarta.

Penelitian lain yang berkaitan dengan alih kode dan campur kode juga pernah dilakukan oleh Pratiwi (2015) yang berjudul "Campur Kode dan Interferensi di Lingkungan Kos Avito". Pratiwi menganalisis campur kode dan interferensi yang terjadi di lingkungan kosnya. Hasil penelitian Pratiwi menunjukkan bahwa campur kode yang terjadi disebabkan oleh situasi dan latar belakang penutur yang memiliki kesamaan. Masing-masing penutur merupakan penutur bahasa Jawa, sehingga dalam berkomunikasi sering mencampur bahasa Jawa dengan bahasa Indonesia. Interferensi juga terjadi karena menyerap afiks-afiks bahasa lain.

Berdasarkan uraian di atas, dapat dikatakan bahwa penelitian mengenai alih kode dan campur kode merupakan suatu kajian yang menarik untuk diteliti. Kedua kajian di atas apabila diamati hanya meneliti alih kode dan campur kode yang dilakukan dalam ruang wilayah cukup sempit. Dalam artian, mitra tutur yang bersentuhan baik secara langsung maupun tidak langsung dengan penutur meliputi komunitas tertentu yang relatif kecil. Adapun alih kode dan campur kode pada Youtuber asing penutur bahasa Indonesia belum banyak dikaji, sehingga penelitian yang berkaitan dengan hal tersebut perlu dilaksanakan untuk memberikan manfaat baik bagi mahasiswa maupun peneliti lain.

\section{Metode}

Penelitian ini merupakan penelitian studi kasus dengan jenis penelitian berupa deskriptif kualitatif yang mendeskripsikan menggunakan kata-kata bukan dalam angka matematis (Lindlof, 1994:2I). Tujuan pemilihan penelitian ini untuk mengungkap berbagai informasi kualitatif dengan deskripsi yang teliti untuk menggambarkan secara cermat berbagai sifat suatu hal, maupun fenomena dan bukan hanya pengumpulan data tetapi juga interpretasi dan analisis mengenai data tersebut(Sutopo, 1996).

Metode pengumpulan data menggunakan teknik simak (teknik simak libat cakap, teknik rekam, dan teknik catat) dan metode cakap (Sudaryanto, 1994). Sumber data yang digunakan berupa konten video Youtuber yang diunduh dari situs Youtube.com. Sumber data yang digunakan merupakan konten video yang telah dilihat oleh paling sedikit 10.000 viewers atau penonton, dan memiliki pelanggan saluran paling sedikit I0.000. Konten video yang diambil berasal dari 
dua Youtuber yaitu Sacha Stevenson dan Felipe Valdes. Dua Youtuber tersebut telah memiliki setidaknya 10.000 pelanggan aktif sehingga memiliki tingkat popularitas yang relatif tinggi. Video Sacha Stevenson (SS) yang digunakan antara lain berjudul Nongkrong di Minimarket :Nasib Saya Nikah (NMNSN); Rahasia Bule yang Masuk TV di Indonesia (RBMI); Bohongan Terbesar (BT); Kamu Butuh ini Njing (KBN), My Boyfried Buys My Outfits (MBBMO). Kemudian video Felipe Valdes (FV) yang digunakan antara lain berjudul Dimana Saya Bisa e-e (DSBE), dan Kapan Nikah (KN).

\section{Hasil dan pembahasan}

Hasil penelitian menunjukkan bahwa pilihan bahasa yang digunakan oleh para Youtuber sangat bervariasi. Penggunaan bahasa Indonesia dan Inggris cukup berimbang dalam konten video. Berdasarkan temuan data, banyak fenomena alih kode dan campur kode, interferensi dan integrasi yang muncul dalam konten video. Alih kode (AK) dan Campur Kode (CK) yang ditemukan bisa muncul dalam satu kalimat, namun banyak juga ditemukan kombinasi antara keduanya dalam satu kalimat. Beberapa temuan menarik berupa kekhasan Youtuberdapat dilihat pada tabel 1 berikut:

Tabel 1. Perbandingan Kekhasan Youtuber

\begin{tabular}{cll}
\hline Penggunaan & \multicolumn{1}{c}{ SS } & \multicolumn{1}{c}{ FV } \\
\hline \multirow{4}{*}{$\begin{array}{c}\text { Pronomina } \\
\text { Persona }\end{array}$} & Saya, I, aku & Aku, \\
& We, kita & Kita \\
\cline { 2 - 3 } & & Kamu \\
& & Kalian \\
\cline { 2 - 3 } & Dia, she, he & Dia, she \\
& Mereka & Mereka \\
\hline Variasi & Indonesia, Inggris, & Indonesia, Inggris, \\
bahasa & Sunda & Jawa \\
\hline Bahasa tabu & bahasa daerah, & Bahasa daerah, \\
& bahasa Inggris & bahasa Inggris \\
\hline
\end{tabular}

Kekhasan yang pertama berupa pengggunaan pronominal persona oleh SS maupun FV. Keduanya sudah menggunakan kata ganti aku dan saya dalam tuturannya, walaupun terkadang SS masih relatif sering menggunakan bahasa Inggris "I". selain itu variasi bahasa yang dipakai oleh keduanya juga tidak hanya menggunakan bahasa Indonesia, tetapi juga menggunakan bahasa daerah berupa bahasa Jawa dan Sunda.

Dalam data video MBBMO ditemukan AK sebanyak 19 buah, CK, 5 buah dan AK \& CK sebanyak 7 buah. Contoh Peristiwa tutur tersebut dapat ditunjukkan dalam tabel 2berikut:
Tabel 2. Transkrip MBBMO

\begin{tabular}{|c|c|c|}
\hline No & Penutur & Tuturan \\
\hline $\mathrm{I}$ & SS & : hay everyone, and welcome back! \\
\hline 2 & ANG & : hai \\
\hline 3 & SS & $\begin{array}{l}\text { : dua minggu belakangan ini saya mulai } \\
\text { like aneh di Youtube. Tapi jangan aneh } \\
\text { terus kan ada batasnya. Aku hari ini } \\
\text { ingin jadi Youtuber yang taat, yang } \\
\text { normal, jadi kita akan ikut tren. Pacar } \\
\text { beliin bajuku. }\end{array}$ \\
\hline 4 & ANG & : emang kamu punya pacar? \\
\hline 5 & SS & $\begin{array}{l}\text { : Angga won't let me get a boyfriend to } \\
\text { do my trend video, so it's gonna be like } \\
\text { suami belanja bajuku. Also good, not as } \\
\text { trendy but it's also it's okay. This is a } \\
\text { what a fashion expert's wearing for } \\
\text { himself, black shirt, same pants wear } \\
\text { every day, and the same sandals. Now } \\
\text { you wear Swallow's? }\end{array}$ \\
\hline 6 & ANG & $\begin{array}{l}\text { : ga havaianas lagi. Mahal, sekarang } \\
\text { tambah mahal. }\end{array}$ \\
\hline 7 & SS & $\begin{array}{l}\text { : jadi Angga akan pergi belanja baju } \\
\text { saya, dan saya akan manjain muka } \\
\text { cantik ini sampai aku cantik banget. } \\
\text { You will never see this face as beautiful } \\
\text { as this ever again, because it's gonna be } \\
\text { more beautiful. It's gonna be shining } \\
\text { bright like a diamond. I'm gonna look } \\
\text { so good, in your cloth that you buy me } \\
\text { from Nirmala. }\end{array}$ \\
\hline 8 & ANG & : saya mau beliin Sacha baju di pasar. \\
\hline 9 & SS & $\begin{array}{l}\text { : That's the way I love about you baby. } \\
\text { Skin Act's? Take your worry off } \\
\text { forever. And that's will we doing today. } \\
\text { We're taking off my worry forever. } \\
\text { And this worry gone. Dia bilang bahwa } \\
\text { saya mungkin butuh Derma Stamped. } \\
\text { So I may get stamped today. It's going } \\
\text { to repair the sign of aging. Calm my } \\
\text { inflammation? Give my skin youthful } \\
\text { glow. Sound of magic! It is a serum, and } \\
\text { then they stamped. I think, I think they } \\
\text { gonna stamped it. Can't wait. Alright } \\
\text { give me the stamp, I want to stamp. }\end{array}$ \\
\hline
\end{tabular}

Pelaku tuturan :penutur adalah perempuan bernama Sacha Stevenson (SS) berkebangsaan Kanada, yang berprofesi sebagai seorang Youtuber. Mitra tutur bernama Angga, pria berkebangsaan Indonesia. Mitra tutur merupakan suami SS

Situasi tuturan :Situasi tidak formal dan terjadi di awal video

Topik :Mengikuti tren di Youtuber dengan tema "pacar membelikan pakaian" 
Lokasi tuturan :Terjadi di rumah penutur dan mitra tutur

Dapat dilihat pada tabel 2 di atas, terdapat fenomena AK, CK, dan kombinasi keduanya yang terjadi dalam satu peristiwa pertuturan. peristiwa AK terjadi pada data [2.I], [2.5], dan [2.7]. Sedangkan peristiwa CK dapat dilihat pada data [2.3]. kemudian peristiwa AK \& CK terjadi pada data [2.9]. Peristiwa AK pada data tersebut dapat ditandai dengan penggunaan bahasa asli penutur - dalam hal ini bahasa Inggris- yang dikaji berdasarkan sosiolinguistik maupun gramatika bahasa(Auer, I999). Susunan kalimat secara lengkap yang memiliki baik subjek maupun predikat ditunjukkan pada ketiga data tersebut.Penggunaan AK semacam ini disebabkan oleh beberapa faktor (Treffers-Daller, 2009)antara lain; pertama faktor independen dari penutur dan keadaan khusus dimana variasi tersebut digunakan dan berdampak pada seluruh variasi relevan penturu dalam masyarakat, contohnya pasar ekonomi. Selanjutnya terdapat faktor yang berhubungan langsung dengan penutur, baik secara individual maupun sebagai bagian dari masyarakat, contohnya hubungan sosial, atitud, dan ideologi. Terakhir berupa faktor dalam percakapan di mana AK tersebut berlangsung. Dalam hal ini, penggunaan AK oleh SS lebih merujuk pada faktor kedua, yaitu berhubungan langsung dengan penuturnya.

Peristiwa CK pada data [2.3] ditunjukkan dengan adanya kata like yang masih dalam tataran kata (Saddhono, 20I2). Kata tersebut memiliki beberapa arti antara lain 'kesukaan','suka', 'sama', dan 'seperti'. Namun, pada konteks tersebut makna kata like lebih merujuk pada 'suka'. Sehingga SS hendak menyampaikan bahwa dia sudah mulai suka aneh dalam membuat konten video di Youtube. Peristiwa CK semacam itu dapat disebabkan adanya beberapa faktor, pertama karena pengetahuan SS pada tataran kata di bahasa Indonesia masih cukup terbatas; kedua SS secara sadar memilih menggunakan kata tersebut karena menjaga makna semantik kalimatnya; ketiga karena SS dipengaruhi oleh faktor tekanan waktu (Isurin, Winford, \& Bot, 2009).

Hal menarik lain yang ditemukan adalah adanya perubahan penggunaan kata ganti dari saya menjadi aku. Kesan saya menjadi lebih formal penggunaannya dibandingkan aku. Disini terlihat bahwa penutur asing menyadari situasi dan konteks yang mendasari peristiwa tutur. Kata Aku merupakan salah satu bentuk adaptasi bahasa Jawa ke dalam bahasa Indonesia, yang mana bahasa Jawa merupakan salah satu pengaruh besar berkembangnya bahasa Indonesia(Mcconvell \& Florey, 2005). Kata aku juga lebih memiliki nilai rasa personal, satu arah, maupun lebih puitis (Saddhono,
20I2). Fenomena masuknya bahasa daerah dalam peristiwa AK dan CK juga dapat dilihat pada tabel 3 berikut.

Tabel 3. Transkrip data BT

\begin{tabular}{|c|c|c|}
\hline No & Penutur & Tuturan \\
\hline I & SS & $\begin{array}{l}\text { : "no ! no, I don't get it! Tidak } \\
\text { mengerti! And you're gonna need } \\
\text { more than a pun! To get me to jump, } \\
\text { on your pee train! Dude!" }\end{array}$ \\
\hline 2 & $S V$ & $\begin{array}{l}\text { : "Upon awakening in the morning } \\
\text { you know, get collect your pee pee in a } \\
\text { bottle or cup whatever, and the drink } \\
\text { itt" }\end{array}$ \\
\hline 3 & SS & $\begin{array}{l}\text { : you know? Whatever!' teu na naon } \\
\text { atuh? Raos, sehat deuy. Iye mah raos" }\end{array}$ \\
\hline 4 & SV & $\begin{array}{l}\text { :"there are many lies circulating in our } \\
\text { society and our world today" }\end{array}$ \\
\hline 5 & $S S$ & $\begin{array}{l}\text { : "Ok By the way, dia tinggal di Iglo } \\
\text { plastik itu. That's his house, I } \\
\text { guatantee it" }\end{array}$ \\
\hline 6 & $S V$ & $\begin{array}{l}\text { :One of the biggest ones, has to do } \\
\text { with urine. because God forbid people } \\
\text { find out that they can cure themselves } \\
\text { for free. Because its pee is free." }\end{array}$ \\
\hline 7 & SS & $\begin{array}{l}\text { : 'mmm...tadi ga ngerti, tapi } \\
\text { sekarangmulai ngerti, I'm getting it } \\
\text { now, I'm connecting the dots. In } \\
\text { tentang lies and deception, dan siapa } \\
\text { yang bohong? 'mereka' yang bohong. } \\
\text { This is life changing. Superindo tidak } \\
\text { mau kamu tahu ini, karena mereka } \\
\text { mau kamu beli pisangnya. Tapi semua } \\
\text { mineral, vitamin, dan serat, kamu bisa } \\
\text { dapat dari sini. You can just eat it, it's' } \\
\text { free!' You got your little flavor!' It's } \\
\text { freel." }\end{array}$ \\
\hline
\end{tabular}

Pelaku tuturan :penutur adalah perempuan bernama Sacha Stevenson (SS) berkebangsaan Kanada, yang berprofesi sebagai seorang Youtuber. SV bukanlah mitra tutur, melainkan Suara Video yang diputar oleh SS. SV merupakan penutur bahasa Inggris dan tidak diketahui menguasai bahasa Indonesia atau tidak.

Situasi tuturan :Situasi tidak formal dan terjadi di pertengahan video

Topik :Mengomentari video minum pipis di Youtube

Lokasi tuturan $\quad$ Terjadi di rumah penutur

Tabel 3 di atas diambil dari video BT yang mendapatkan temuan AK sebanyak 6, CK sebanyak 3, dan AK \& CK sebanyak 9. Penggunaan AK \& CK hampir mendominasi seluruh peristiwa tuturan dalam 
video ini. Temuan CK dapat dilihat pada data [3.7] dengan kata lies and deception. Bentuk lies and deception tidaklah dapat dikategorikan sebagai kalimat karena tidak memiliki subjek dan predikat. Bentuk tersebut hanya berupa frasa yang terdiri atas dua nomina serta satu konjungsi.

Selain penggunaan bahasa Inggris dan bahasa Indonesia, SS juga melakukan tuturan dengan menggunakan bahasa Sunda. Peristiwa ini dipengaruhi oleh hubungan suami-istri dengan Angga yang merupakan pria suku Sunda. Selain identitas sosial, identitas kebudayaan dan identitas etnis memainkan peran dalam peristiwa alih kode(Luciana, 20I5). Sehingga pengaruh dari identitas etnis dari Angga selaku suami dari SS memberi pengetahuan seputar produk kebudayaan utamanya bahasa Sunda.

Walaupun tidak diketahui seberapa mahir SS dalam menggunakan bahasa Sunda, pengucapan "teu na naon atuh? Raos, sehat deuy. Iye mah raos" yang memiliki arti "tidak apa apa kok? Rasanya enak, iya enak" sudah cukup lancar ditandai dengan penggunaan intonasi sunda yang khas oleh SS. Temuan lain yang menunjukkan penguasaan bahasa Sunda oleh SS dapat dilihat pada tabel 4 berikut:

Tabel 4. Transkrip data KBN

\begin{tabular}{|c|c|c|}
\hline No & Penutur & Tuturan \\
\hline I & SS & $\begin{array}{l}\text { : see? He thinks that because he doesn't } \\
\text { need a month, that nobody needs a } \\
\text { month. I needed my woman history } \\
\text { month. And you need your month. } \\
\text { What's your month? }\end{array}$ \\
\hline 2 & ANG & : saya ga punya \\
\hline 3 & SS & $\begin{array}{l}\text { : See? He must like Morgan. He must } \\
\text { already gotta your month! And now you } \\
\text { don't have one! That's probably why } \\
\text { you get your butt groped. Banyak } \\
\text { masalah di dunia, masa dia ga punya } \\
\text { solusinya. Ya beranilah, ya kuatlah. It's } \\
\text { a stupid message! }\end{array}$ \\
\hline 4 & SS & $\begin{array}{l}\text { : this is disgusting, the bus runs } \\
\text { everyday. That's great for him. But cute } \\
\text { little guy like you? Gets on the } \\
\text { bus?You'te gonna get butt groped, all } \\
\text { the way to Jogja! What we have to do is } \\
\text { we have to stop focusing on our } \\
\text { personal goals, and start focusing on the } \\
\text { Cunihin (Creepy man). We have to } \\
\text { change theCunihin. Mereka hidupnya } \\
\text { sudah terlalu enak, harus dijatuhkan. So, } \\
\text { right? Banyak aksi, okey. Ini aksi lagi } \\
\text { nih. }\end{array}$ \\
\hline
\end{tabular}

Pelaku tuturan :Penutur SS bersama mitra tutur ANG .

Situasi tuturan :Situasi tidak formal dan terjadi di akhir video
Topik

Lokasi tuturan

:Mengatasi tindakan pelecehan seksual

:Terjadi di rumah penutur

Temuan lain penggunaan bahasa Sunda dapat dilihat dalam video KBN pada data [4.4]. SS menggunakan istilah cunihin yang dalam bahasa Indonesia berarti 'pria yang suka mengganggu ataupun mengejek orang lain utamanya wanita'. Studi oleh Kharkhurin (Kharkhurin, 20II) menyebutkan bahwa peran bahasa, wilayah, dan lokasi budaya dapat meningkatkan pemikiran kreatif seseorang. Sehingga dapat disimpulkan bahwa penggunaan bahasa daerah dapat diidentifikasikan sebagai bentuk kreatif dari SS yang dipengaruhi oleh faktor budaya. Kebudayaan khas Sunda yang diketahui oleh SS tidak terlepas juga dari faktor hubungan keluarga yang dimiliki oleh SS. Suami SS merupakan seorang pria bersuku Sunda. Sehingga jelas pengetahuan akan kebudayaan Sunda ini dimiliki SS karena pengaruh suaminya. Selain itu, pada KBN ditemukan AK sejumlah I2, CK sebanyak 2 dan AK \& CK sebanyak 6.

Selain penggunaan bahasa Sunda, SS juga sering menggunakan diksi slang Indonesia seperti pada data berikut:

[2.10] "you bought me sweatpants? Oke, for one I love them. I love this. mmm... Aku pikir kamu beliin aku ini biar aku, tidak dapat pacar. Ini ada banyak ruang gerak di sini, jadi kalo saya...ga tahu dah. Gimana? I'm gonna wear them. I'm totally gonna weat them." (MBMO)

[2.II] SS : okay. Mmmm.... I'm not really wear on it. Seperti mau sikat WC. Tapi makasih. Makasih (MBMO)

[3.8] "Heyguys and welcome back, saya cape lah bahasa yang berat-berat di Youtube, baca komenjahat-lah ini -lah itu lah, saya ini mau nikmatin hidup, gamau banyak ngomong, otak saya? Turn off, pokoknya relax dah, kita relax sambil nonton infotainment ya? Ringan tuh, infotainment." (BT)

[3.9] "and that! It's all what's going down! Jamin! Nobodies gonna dating you if you doing this! Ini buat jomblo doang, ini. Gak ada cowok Indonesia yang...pokoknya jomblo ya. Gapapajomblo, gapapa. Just Saying it!' (BT)

[4.5] from my diafragma. Bisa sambil naikin tangan, see? This will improve the quality of your life! Together we will break the walls of oppression with this strategy. $(\mathrm{KBN})$ 
[4.6] ini efektif, Angga! Lalu kamu bisa sejago ini orang. Ini dia mengeluarkan handphone, lalu dia hajar si pelaku. Okey, Like this. Ini contoh yang bagus. (KBN)

Pada data yang dicetak tebal di atas, dapat dilihat penggunaan diksi yang cenderung termasuk pada diksi slang di bahasa Indonesia. SS sudah dapat menggunakan partikel yang khas digunakan oleh penutur asli bahasa Indonesia, seperti "dah", "tuh", "lah". Partikel-partikel semacam itu sebenarnya tidak memiliki arti khusus, namun lebih umum digunakan untuk tuturan yang sifatnya lebih nonformal.

Selain penggunaan partikel, SS juga kerap menggunakan bahasa Slang di Bahasa Indonesia. Diksi seperti "jomblo", "cowok" merupakan diksi yang secara fungsional termasuk diksi bahasa slang. Kecenderungan memakai diksi tersebut dipengaruhi oleh lingkungan tempat tinggal dan mitra tutur SS yang juga kemungkinan besar memakai diksi tersebut juga. Sama seperti munculnya bahasa daerah yang dituturkan oleh SS.

Faktor tersebut juga yang sepertinya mempengaruhi kemampuan SS dalam menggunakan bahasa Indonesia yang cenderung disingkat. Seperti penggunaan kata "gimana" dari kata bagaimana, "ga" dari kata tidak, "makasih" dari kata terima kasih, "gapapa" dari kata tidak apa-apa, serta kata "naikin" dari kata menaikan. Diksi-diksi tersebut cenderung lebih sering digunakan oleh penutur asli dalam bahasa Indonesia, karena sifatnya yang lebih singkat dan efisien tanpa mempengaruhi makna informasi yang hendak disampaikan. Walaupun secara fungsional diksi-diksi tersebut termasuk dalam kosakat bahasa Indonesia tidak baku, sehingga SS dalam hal ini sudah cukup mahir menggunakan bahasa Indonesia lebih fleksibel.

Selain munculnya istilah tertentu bahasa daerah, terkadang dalam bentuk tuturan oleh penutur asing muncul beragam istilah yang sebenarnya termasuk dalam kosakata tabu. Salah satunya penggunaan kosakata yang menunjukkan kelamin manusia, maupun berhubungan dengan seksualitas karena dianggap tabu dan terlarang secara sosial(Rosenberg \& Garcia, 2016). Temuan yang berkaitan dengan penggunaan istilah tabu tersebut dapat dilihat pada tabel 5 berikut:

Tabel 5. Transkrip data DSBE

\begin{tabular}{|c|c|c|}
\hline No & Penutur & Tuturan \\
\hline I & FFV & $\begin{array}{l}\text { : hai semua, apa kabar kamu? Hari ini } \\
\text { aku akan berbicara tentang video dari } \\
\text { youtube. Ini ada orang bule aku ga tahu } \\
\text { darimana. Dia mau mengajar bahasa } \\
\text { Indonesia, tapi... Ayo nonton } \\
\text { bersama. }\end{array}$ \\
\hline 2 & SV & hallo, apa kabar? Nama say \\
\hline
\end{tabular}

\begin{tabular}{|c|c|c|}
\hline & & Nger \\
\hline 3 & FFV & $\begin{array}{l}\text { : wait, wait, wait. Tunggu! The girl } \\
\text { starts the video saying 'ngentot luh' } \\
\text { what the hell is that? Oke let's keep } \\
\text { watching. }\end{array}$ \\
\hline 4 & SSV & $\begin{array}{l}\text { : in Indonesian we vowel lot ' } T \text { ' rrrr... } \\
\text { apa kabar? How are you? Kabar baik. } \\
\text { I'm fine. Terima kasih. Thank you. } \\
\text { Nama saya Silvia. My name is Silvia. } \\
\text { Barusan saya kentut. I need your } \\
\text { assistance. }\end{array}$ \\
\hline 5 & FFV & $\begin{array}{l}\text { : what? Stop stop stop.... It doesn't } \\
\text { mean 'I need your assistance'it means } \\
\text { another thing. Oke oke oke, let's keep } \\
\text { watching. }\end{array}$ \\
\hline 6 & SSV & $\begin{array}{l}\text { : dimana saya bisa e-e? Where is the } \\
\text { toilet? }\end{array}$ \\
\hline 7 & FFV & $\begin{array}{l}\text { : no! if you wanna ask where is the } \\
\text { toilet you can say dimana toilet, tapi } \\
\text { dimana saya bisa e-e' means another } \\
\text { thing. }\end{array}$ \\
\hline
\end{tabular}

Pelaku tuturan

:penutur adalah pria bernama Felipe Valdes (FV) berkebangsaan Brazil, yang berprofesi sebagai seorang Youtuber. SV bukanlah mitra tutur, melainkan Suara Video yang diputar oleh SS. SV merupakan penutur bahasa Inggris dan diketahui menguasai bahasa Indonesia

Situasi tuturan :Situasi tidak formal dan terjadi di awal video

Topik :Mengomentari pengajaran bahasa Indonesia oleh SV

Lokasi tuturan :Terjadi di rumah penutur

Tabel 5 di atas merupakan video DSBE . Pada data tersebut ditemukan temuan AK sejumlah I5, kemudian CK sejumlah I, dan AK \& CK sejumlah IO. Hal yang sangat menarik ditemukan pada data [4.2] dan [4.3]. Dimana ditemukan kosakata yang dianggap tabu yaitu ngentot. Ngentot sendiri merupakan bentuk yang dianggap sangat kasar dari kata kawin. Penggunaan kosakata ngentot lebih banyak ditemukan pada bahasa umpatan, karena banyak digunakan untuk memaki. Namun, dilihat dari konteksnya penutur SV tidak memahami apa yang dimaksud dengan kata ngentot.

Hal ini dapat menyebabkan sebuah simpulan, yaitu penutur SV yang belajar bahasa Indonesia melalui penutur yang tidak bertanggung jawab. Ketidaktahuan mengenai mana kosakata yang tabu dalam suatu bahasa cenderung terjadi karena kosakata tersebut jarang digunakan dalam peristiwa tuturan normal, melainkan dalam konteks tertentu misalnya mengumpat. Tuturan yang berkaitan dengan 
seksualitas, baik penyebutan kelamin maupun praktik seks dianggap tidak nyaman digunakan dalam komunikasi (Hudson \& Okhuysen, 20I4).

Tabel 6. Data transkrip KN

\begin{tabular}{|c|c|c|}
\hline No & Penutur & Tuturan \\
\hline I & FV & $\begin{array}{l}\text { hai semua? Apa kabar kamu? Today } \\
\text { I'm gonna answer some question's } \\
\text { people send me by facebook, } \\
\text { instagram. Dan aku akan berbicara } \\
\text { dalam bahasa Indonesia, bahasa } \\
\text { Inggris, karena aku belum tahu } \\
\text { semua tentang bahasa Indonesia. }\end{array}$ \\
\hline 2 & FVP & Felipe? Udah pulang kampung? \\
\hline 3 & $\mathrm{FV}$ & belum, aku tinggal di Jakarta \\
\hline 4 & FVP & $\begin{array}{l}\text { kapan ke Semarang lagi? Ke } \\
\text { Karangturi. }\end{array}$ \\
\hline 5 & $\mathrm{FV}$ & $\begin{array}{l}\text { Aku rindu Karangturi, aku cinta } \\
\text { kalian }\end{array}$ \\
\hline 6 & FVP & lagu Indonesia favorit Felipe. \\
\hline 7 & $\mathrm{FV}$ & $\begin{array}{l}\text { lagu Indonesia favoritku Matahariku. } \\
\text { Ini pertama lagu aku tahu lagu dari } \\
\text { Indonesia, Agnes Monica } \\
\text { Matahariku }\end{array}$ \\
\hline
\end{tabular}

Kekhasan penutur asing dalam menuturkan lain yang bukan bahasa penutur adalah terjadinya interferensi, yaitu pengaruh satu bahasa terhadap bahasa lain (Treffers-Daller, 2009). Fenomena in terjadi karena adanya ketidakmampuan penutur dalam mengontrol $\mathrm{AK}$ dan transfer informasi. Interferensi yang muncul dapat dilihat pada data [6.I], [6.6] dan [6.7] di atas, dimana pengaruh dari bahasa Inggris masih dapat dirasakan dalam kalimat FV. Interferensi ini termasuk jenis interferensi statis, yaitu interferensi yang mempengaruhi susunan gramatika bahasa (Treffers-Daller, 2009).

Misalnya dalam kalimat:

[6.1] "apa kabar kamu?"

[6.5] "aku cinta kalian"

Pada kalimat [6.I] kalimat "apa kabar kamu?" secara struktur sintaksis bahasa Indonesia dianggap benar, namun kurang berterima. Umumnya, penutur asli bahasa Indonesia akan mengucapkan "bagaimana kabarmu?" alih-alih menggunakan kalimat "apa kabar kamu?”. Karena selain dirasa lebih efektif, kalimat tersebut cenderung lebih berterima dalam konteks sosial. Kalimat "apa kabar kamu” lebih merujuk pada makna semantis kalimat "how are you" dalam bahasa Inggris, sehingga interferensi dari bahasa Inggris cukup jelas dalam tuturan tersebut.

Contoh lain pada kalimat [6.6], FV menggunakan diksi "cinta" dalam kalimat "aku cinta kalian”. Kalimat ini juga kurang umum bila dipergunakan dalam komunikasi menggunakan bahasa Indonesia. Penutur asli bahasa Indonesia cenderung mempertimbangkan subjek komunikan untuk memakai diksi "cinta". Umumnya, diksi "cinta" ditujukan kepada subjek tunggal yang memiliki hubungan lebih intim dengan komunikator, sebagai contoh suami ataupun istri. Hal tersebut dikarenakan penggunaan diksi "cinta" mempunyai rasa yang lebih kuat dibandingkan dengan diksi yang semakna seperti misalnya "sayang". Sedangkan untuk subjek yang lebih jamak dan tidak memiliki hubungan lebih intim dengan komunikator, cenderung digunakan kata "sayang" yang mempunyai cakupan rasa lebih luas namun semakna dengan kata "cinta".

Penggunaan diksi "cinta" tak lepas dari pengetahuan bahasa kedua penutur yaitu bahasa Inggris. Baik kata "cinta" dan "sayang" sama-sama memiliki asosiasi dengan kata "love" dalam bahasa Inggris. Dengan kata lain, pemilihan diksi oleh FV masih kurang tepat dan cenderung tidak mempertimbangkan faktor komunikan. Penutur asing cenderung tidak memperhatikan penggunaan kata ganti persona yang ditempatkan di belakang nomina maupun keterangan, hal tersebut dapat dilihat pada data berikut:

Tabel 6.I Data transkrip KN

\begin{tabular}{lll}
\hline No & Penutur & Tuturan \\
\hline 7 & FVP & gimana rasanya tinggal di Indonesia? \\
\hline 8 & FV & $\begin{array}{l}\text { I love living here. Panas orang-orang } \\
\text { keren. Aku suka makanan, it's } \\
\text { perfect }\end{array}$ \\
& &
\end{tabular}

\begin{tabular}{lll}
\hline 9 & FVP & $\begin{array}{l}\text { kenapa suka banget sama Agnes } \\
\text { MO?. }\end{array}$ \\
\hline I0 & FV & $\begin{array}{l}\text { karena Agnes cantik. Aku suka lagu- } \\
\text { lagu, she is very talented, and Agnes } \\
\end{array}$ \\
& Monica inspirasi
\end{tabular}

Dapat dilihat pada data 6.8 dan 6.10 yang dicetak tebal di atas, bahwa konstruksi kalimat yang dituturkan oleh FV tidak memiliki kata ganti yang mengacu pada subjek sebelumnya.

\section{[6.8] "aku suka makanan” \\ [6.10] "aku suka lagu-lagu"}

Pada kalimat tersebut seharusnya menyertakan acuan subjek yang dirujuk. Normalnya, penutur asli bahasa Indonesia akan menyertakan pronomina 'nya' di belakang kedua kalimat tersebut, sehingga akan berbunyi sebagai berikut:

\section{[6.8] "aku suka makanannya"}

[6.I0] "aku suka lagu-lagunya"

Dengan merujuk pada konteks tuturan yang dilakukan oleh kedua penutur, maka pronomonima pada kedua kalimat tersebut menjadi penting karena 
akan menjelaskan subjek manakah yang dijadikan acuan pemilik oleh FV.

\section{Simpulan}

Youtuber asing yang berbahasa Indonesia memiliki kekhasan dalam menggunakan bahasa Indonesia. Munculnya Campur Kode dan Alih Kode menggunakan bahasa Inggris merupakan bukti tuturan mereka masih dipengaruhi oleh bahasa Inggris cenderung sebagai suatu bentuk spontanitas dan ketidaksengajaan. Hal tersebut wajar dikarenakan penguasaan bahasa Indonesia mereka masih belum berada di tingkatan yang dapat dikatakan sangat mahir.

Kebudayaan juga turut mempengaruhi bentuk tuturan mereka. Hubungan pernikahan menjadi salah satu faktor yang mempengaruhi bentuk tuturan. Salah satunya adalah penggunaan bahasa daerah berupa bahasa Sunda untuk menuturkan idiom tertentu yang disebabkan oleh adanya ikatan keluarga dengan penutur yang memiliki penguasaan bahasa daerah. Kekhasan lain yang ditemukan adalah penggunaan bahasa tabu berupa penyebutan aktivitas dan jenis kelamin oleh penutur asing. Salah satu penyebab terjadinya hal tersebut adalah ketidaktahuan penutur asing dalam memahami bahasa tabu, karena bahasa tersebut jarang digunakan dalam situasi tuturan normal

Simpulan ditulis secara singkat, padat dan jelas dalam satu paragraf, yang merupakan ringkasan dari hasil dan pembahasan serta menjawab dari tujuan dari penelitian/publikasi. Menekankan pada kebaharuan dari penemuan atau pengembangan.Apabila terdapat saran dari penelitian yang berkaitan dengan hasil penelitian untuk kegiatan praktis ataupun penelitian lanjutan berdasarkan hasil kebaharuan yang ditemukan dapat disampaikan secara singkat dan jelas pada akhir paragraf atau dapat membuat paragraf baru.

\section{Daftar Pustaka}

Alexa. (2017). Alexa Top 500 Global Sites. Retrieved April 30, 2018, from

https://www.alexa.com/topsites

Auer, P. (1999). Code-Switching in Conversation. In P. Auer (Ed.), Code-Switching in Conversation: Language, interaction, and Identity (p. 3). London: Routledge.

Gort, M. (2012). Code-Switching Patterns in the Writing-Related Talk of Young Emergent Bilinguals. Journal of Literacy Research, 44(I), 45-75. https://doi.org/IO.I I77/I086296XI I43I 62 6
Hudson, B. A., \& Okhuysen, G. A. (20I4). Taboo

Topics : Structural Barriers to the Study of Organizational Stigma. Journal of Management Inquiry, 23(3), 242-253.

https://doi.org/IO.I I77/I0564926135I75I0

Indefrey, P., \& Gullberg, M. (2009). Time to Speak: Cognitive and Neural Prerequisites for Time in Language. Time to Speak: Cognitive and Neural Prerequisites for Time in Language. https://doi.org/I0.1002/9781444309645

Isurin, L., Winford, D., \& Bot, K. de (Eds.). (2009). Multidisciplinary Approaches to Code Switching. Amsterdam: John Benjamins Publishing Company.

Kharkhurin, A. V. (20I I). The Role of Selective Attention in Bilingual Creativity The Role of Selective Attention in Bilingual Creativity, (December 20I4), 37-4I. https://doi.org/I0.1080/I04004I9.201 I.595 979

Luciana. (2015). Code-Switching in Indonesian Radio and Television Programs : Linguistic and Sociolinguistic Perspectives. Asian Englishes, (I), 4-23.

https://doi.org/I0.I080/I3488678.2006.108 OII74

Mcconvell, P., \& Florey, M. (2005). Introduction : Language Shift, Code- mixing and Variation. Australian Journal of Linguistics, 25(April 2005), I-7. https://doi.org/I0.1080/07268600500I 1044 9

RISTEKDIKTI. (2017). Perguruan Tinggi Indonesia Diminati Mahasiswa Asing - Ristekdikti. Retrieved April 30, 20I8, from https://ristekdikti.go.id/perguruan-tinggiindonesia-diminati-mahasiswa-asing-2/

Rosenberg, P., \& Garcia, D. (2016). The A (ffective) B (ehavioral ) C ( ognitive) of Taboo Words in Natural Language: The Relationship Between Taboo Words 'Intensity and Frequency. Journal of Language and Social Psychology, I-I5. https://doi.org/I0.I I77/026I927XI666083 0

Saddhono, K. (2012). Kajian Sosiolingustik Pemakaian Bahasa Mahasiswa Asing Dalam Pembelajaran Bahasa Indonesia Untuk Penutur Asing (Bipa) Di Universitas Sebelas Maret. Kajian Linguistik Dan Sastra, 24(2), I76-I86. Retrieved from http://journals.ums.ac.id/index.php/KLS/artic 
le/view/96

Sudaryanto. (1994). Metode dan Aneka Teknik

Pengumpulan Data dalam Rangka Linguistik:

Prinsip-prinsip dan Konsep-konsep Dasar.

Yogyakarta: Masyarakat Linguistik Indonesia.

Sudaryanto. (20I4). BIPA di Mata Badan Bahasa:

Pemutakhiran Peta Penyelenggara Program

BIPA di Tiongkok pada Laman Badan Bahasa.

Bahastra, XXXII(I), 65-80.

Sukmana, Y. (2017). UNCTAD : Dari Posisi 8 ,

Indonesia Kini Posisi 4 Negara Tujuan Investasi.

Retrieved November 2I, 2017, from

http://ekonomi.kompas.com/read/2017/06/

08/I20000726/unctad.dari.posisi.8.indonesia.k

ini.posisi.4.negara.tujuan.investasi

Sutopo, H. B. (1996). Metodologi Penelitian

Kualitatif: Metodologi Penelitian untuk Ilmu-

ilmu Sosial Budaya. Surakarta: Sebelas Maret

University Press.

https://doi.org/IO.I I77/I3548565I5579847

Treffers-Daller, J. (2009). Code-Switching and transfer: an Exploration of similarities and Differences. In B. E. Bullock \& A. J. Toribio (Eds.), Linguistic Code-Switching (p. 6I). New York: Cambridge Unversity Press.

Worldbank. (2018). Population ranking (POP) I Data Catalog. Retrieved April 30, 2018, from https://datacatalog.worldbank.org/dataset/pop ulation-ranking 